\title{
A comparative study of the mechanical behaviour of thermally oxidized commercially pure titanium and zirconium
}

\author{
A. Alansari and Y. Sun* \\ School of Engineering and Sustainable Development \\ Faculty of Technology \\ De Montfort University \\ Leicester, LE1 9BH, UK \\ * Corresponding author: Email : ysun01@dmu.ac.uk; Tel: (44) 1162577072
}

\begin{abstract}
The objective of this study is to compare the mechanical behaviour of thermally oxidised commercially pure titanium $(\mathrm{CP}-\mathrm{Ti})$ and commercially pure zirconium $(\mathrm{CP}-\mathrm{Zr})$. For this purpose, these two bio-metals were thermally oxidised under the same condition $\left(650{ }^{\circ} \mathrm{C}\right.$ for $6 \mathrm{~h}$ ) and the oxidised specimens were characterised using various analytical and experimental techniques, including oxygen uptake analysis, layer thickness and hardness measurements, scratch tests, dry sliding friction and wear tests and tribocorrosion tests in Ringer's solution. The results show that under the present thermal oxidation condition, 4 times more oxygen is introduced into $\mathrm{CP}-\mathrm{Zr}$ than into $\mathrm{CP}-\mathrm{Ti}$ and the oxide layer produced on $\mathrm{CP}-\mathrm{Zr}$ is nearly 6 times thicker than that on CP-Ti. Thermally oxidised CP-Zr possesses a higher hardness, a deeper hardening depth and better scratch resistance than thermally oxidised CP-Ti. Under dry sliding and tribocorrosion conditions, thermally oxidised $\mathrm{CP}-\mathrm{Zr}$ also possesses much better resistance to material removal and a higher load bearing capacity than thermally oxidised CP-Ti. Thus, thermally oxidised $\mathrm{Zr}$ possesses much better mechanical behaviour than thermally oxidised $\mathrm{Ti}$.
\end{abstract}

Keywords: titanium, zirconium, oxidation, wear, tribocorrosion 


\section{Introduction}

Titanium (Ti) and zirconium ( $\mathrm{Zr})$ are bio-metals that are used in the biomedical sector to make medical devices and implants (Byeli et al., 2012; Chevalier, 2006; Gepreel and Niinomi, 2013). They possess a good combination of strength, corrosion resistance and biocompatibility, which are desirable as biomaterials (Niinomi, 2002). Both metals have a hexagonal close packed (HCP) crystal structure at room temperature and derive their corrosion resistance and passivity by the naturally occurring oxide film at the surface. Both $\mathrm{Ti}$ and $\mathrm{Zr}$ are also known to possess poor tribological properties. When in contact motion with themselves or other materials, they suffer from severe metallic wear with the tendency towards galling and seizure (Haygarth and Fenwick, 1984; Bloyce, 1998; Byeli et al., 2012). Thus, the uses of $\mathrm{Ti}$ and $\mathrm{Zr}$ have been restricted to mostly non-tribological applications. However, with proper surface modification to alter the surface chemical, physical and mechanical properties, $\mathrm{Ti}$ and $\mathrm{Zr}$ and their alloys can be used to make bearing components such as in artificial hip and knee joints (Dong and Bell, 1999; Hunter et al., 2002).

Thermal oxidation offers a simple and cost-effective way to modify the surfaces of $\mathrm{Ti}$ and $\mathrm{Zr}$ and their alloys to achieve much enhanced tribological and bio-tribological properties (Bloyce et al., 1998; Guleryuz and Cimenoglu, 2004; Haygarth and Fenwick, 1984; Pawar et al., 2011; Ji et al., 2010; Kumar et al., 2010; ). Indeed, thermally oxidised Ti alloys have been reported to have the potential use in artificial hip joints (Yamamoto et al., 2009; Wang et al., 2014b; Lieblich et al., 2016), and thermally oxidized $\mathrm{Zr}$ has recently been introduced as an alternative bearing in total joint arthroplasty for artificial knee and hip joints (Patel and Spector, 1997; Good et al., 2005; Galetz et al., 2010; Innocenti et al., 2014). Thermally oxidised Ti and $\mathrm{Zr}$ possess the desirable combination of a ceramic bearing surface to resist wear and a tough metallic core to resist fracture (Bell et al., 1998; Pawar et al., 2011; Alansari and Sun, 2017).

Both $\mathrm{Ti}$ and $\mathrm{Zr}$ are reactive metals with a high affinity with oxygen to form an oxide film easily. They can also dissolve a large amount of oxygen in the HCP lattice to form a solid solution with a significant hardening effect. Thermal oxidation is normally carried out at temperatures between $500{ }^{\circ} \mathrm{C}$ and $700{ }^{\circ} \mathrm{C}$ in ambient atmosphere or in controlled atmospheres. During thermal oxidation, oxygen diffuses into the $\mathrm{CP}$ materials to form an oxygen diffusion zone (ODZ) with interstitial solid solution hardening, and once the surface is saturated with oxygen, an oxide layer (OL) develops at the surface. Thus thermally 
oxidised CP-Ti and CP-Zr comprise an OL at the surface and a hardened ODZ in the subsurface (Dong and Bell, 1999; Alansari and Sun, 2017; Ji et al., 2010; Bailey and Sun, 2013). The OL can improve frictional characteristics and offer wear resistance, while the ODZ can offer load bearing capacity. However, the quality of the OL depends on thermal oxidation conditions, such as temperature and time. High temperature and/or long time oxidation would produce a none-adherent, fragile and crumbly OL on $\mathrm{Ti}$, which has a tendency to delaminate from the substrate (Bailey and Sun, 2013; Biswas and Majumdar, 2009; Sun et al., 2016). Similarly, oxidation breakaway would occur to $\mathrm{Zr}$ during high temperature or long time oxidation, characterised by the formation of pore and cracks in the OL (Wallwork et al. 1965; Ploc, 1980; Maekawa and Ishii, 1962). It has been observed that an oxidation temperature between $600^{\circ} \mathrm{C}$ and $700^{\circ} \mathrm{C}$ offers the best compromise between generating a sufficiently thick oxide layer and maintaining good adhesion between the OL and the substrate for both Ti and Zr (Krishna et al. 2007; Wang et al. 2014a; Pawar et al., 2011).

Despite the extensive research in recent years on thermal oxidation of $\mathrm{Ti}$ and $\mathrm{Zr}$ for enhanced tribological properties and biomedical applications, no studies have been reported to directly compare their oxidation behaviour and their mechanical performances after thermal oxidation. Due to the importance of these two bio-metals and their ability to be hardened by oxidation, it is necessary to compare the thermal oxidation behaviour of these two bio-metals and their response to mechanical and combined mechanical and chemical actions. In this investigation, commercially pure $\mathrm{Ti}$ and $\mathrm{Zr}$ were thermally oxidised under the same condition. Using the same oxidation condition provides a direct comparison of the oxidation behaviour and the resultant mechanical properties of the two biometals. The oxidised specimens were compared in terms of layer thickness, hardness, scratch resistance, and tribological behaviour under dry unlubricated conditions and tribocorrosion behaviour under simulated physiological conditions.

\section{Material and Methods}

\subsection{Materials and thermal oxidation}

Commercially pure titanium (CP-Ti) grade 2 (99.4\% purity) and commercially pure zirconium (CP-Zr) grade 2 (99.2\% purity) were used in this work. The original metallurgical structure of these CP materials comprised HCP $\alpha$-phase. Specimens of $20 \mathrm{~mm}$ x $15 \mathrm{~mm}$ x 1 
$\mathrm{mm}$ were prepared by machining the as-received plates. The specimens were wet ground using metallographic SiC grinding papers down to the P1200 grade, then polished in 6 micron diamond suspensions for $5 \mathrm{~min}$, and finally finished by polishing in silica suspensions for 40 min to achieve a mirror-like surface finish of $0.03 \mu \mathrm{m}\left(\mathrm{R}_{\mathrm{a}}\right)$.

Before thermal oxidation (TO), the specimens were ultrasonically cleaned in methanol for 10 min, thoroughly dried in a stream of hot air, and weighed using an analytical balance accurate to $0.1 \mathrm{mg}$. After TO, the specimens were weighed again to obtain the total mass gain by each type of specimens. The total mass gain was divided by the total surface area of the specimens to obtain the mass gain per unit surface area $\left(\mathrm{mg} \mathrm{cm}^{-2}\right)$. This provides information regarding oxygen uptake by the $\mathrm{CP}-\mathrm{Ti}$ and $\mathrm{CP}-\mathrm{Zr}$ specimens during the TO process.

Thermal oxidation was conducted in an air furnace at a constant temperature of $650{ }^{\circ} \mathrm{C}$ for a constant time of $6 \mathrm{~h}$. After $6 \mathrm{~h}$ at $650{ }^{\circ} \mathrm{C}$, the specimens were allowed to cool slowly in the furnace down to room temperature. This TO condition was chosen based on many preliminary experiments and previous work, which can produce an adherent oxide layer at the surface and an oxygen diffusion zone in the subsurface of CP-Ti and Ti alloys (Sun et al., 2016; Aniolek et al., 2016; Bailey and Sun, 2013) and in CP-Zr and Zr alloys (Pawar et al., 2011; Alansari and Sun, 2017). This condition also ensured that no phase transformation took place in the core of the $\mathrm{CP}$ materials because the oxidation temperature was below the $\alpha-\beta$ transformation temperatures.

\subsection{Characterisation of TO specimens}

After TO, the specimens were characterised by (1) surface roughness measurements using a contact mode profilometer (Mitutoyo SJ-400); (2) surface hardness measurements using a micro Vickers hardness tester (Indentc ZHV) at various loads from 0.025 to $1.0 \mathrm{~kg}$; (3) X-ray diffraction (XRD) analysis using $\mathrm{Cu}-\mathrm{K}_{\alpha}$ radiation to identify the phases of thermally oxidised specimens; (4) microscopic examination of the cross sectional morphology and measurement of the thicknesses of the oxidised layers; (5) micro Vickers hardness profile measurements across the oxidised layers in the cross section using an indentation load of $0.025 \mathrm{~kg}$; and (6) scratch testing of the oxidised surface using a Rockwell diamond tip with a radius of $200 \mu \mathrm{m}$ under various constant loads from $1 \mathrm{~N}$ to $30 \mathrm{~N}$. After scratch testing, the width of each resultant scratch mark was measured and the morphology of the scratch was examined 
microscopically to assess the failure modes and the critical failure load of the oxide layer. A ball crater of about $1 \mathrm{~mm}$ diameter was also made on the scratch by rotating a bearing steel ball of $25.4 \mathrm{~mm}$ diameter at the same spot at a speed of 60 revolutions per minute to provide an inclined and enlarged view of the deformation behavior beneath the scratch. Fig. 1 shows a typical scratch on the TO-Zr surface and a ball crater made on the scratch which provides a clear view of the scratch depth and the deformation of the OL towards the substrate. By zooming in the highlighted rectangular zone, the deformation and crack penetration behaviour could be more clearly observed.

\subsection{Dry sliding wear and tribocorrosion tests}

Dry sliding friction and wear tests were conducted using a laboratory-scale reciprocating wear tester. During the test, the specimen reciprocated linearly at a frequency of $1 \mathrm{~Hz}$ and amplitude of $8 \mathrm{~mm}$. The contacting counterface was an $8 \mathrm{~mm}$ diameter alumina ball (Grade $25 \mathrm{Al}_{2} \mathrm{O}_{3}$ supplied by Trafalgar Bearings Ltd) due to its inertness and high hardness. The tests were carried out at room temperature $\left(22^{\circ} \mathrm{C}\right)$, in ambient environment for duration of $3600 \mathrm{~s}$. During the test, the coefficient of friction (COF) was recorded by a computer data acquisition system. The contact loads ranged from $1 \mathrm{~N}$ to $20 \mathrm{~N}$. Hertzian contact stress calculation showed that these contact loads resulted in initial maximum contact pressures ranging from $468 \mathrm{MPa}$ to $1272 \mathrm{MPa}$ for the Ti specimens and from $412 \mathrm{MPa}$ to $1119 \mathrm{MPa}$ for the $\mathrm{Zr}$ specimens. All tests were duplicated and the mean results are presented.

Tribocorrosion tests were conducted using the same reciprocating wear tester at a reciprocating frequency of $1 \mathrm{~Hz}$ and amplitude of $8 \mathrm{~mm}$. The tests were carried out by immersing the test specimen in $1 \mathrm{M}$ Ringer's solution maintained at $37^{\circ} \mathrm{C}$, contained in a tribo-electrochemical cell made of an insulating material, nylon. An alumina ball of $8 \mathrm{~mm}$ diameter was used as the slider and the applied contact loads ranged from $1 \mathrm{~N}$ to $20 \mathrm{~N}$. All tests were conducted at open circuit without externally applied potential. Before each test, the specimen was stabilised at open circuit for $300 \mathrm{~s}$ without contact with the slider. After sliding for $3600 \mathrm{~s}$, the specimen was left in the solution for further $300 \mathrm{~s}$ without contact with the slider. The open circuit potential (OCP) was recorded continuously before, during and after sliding. An ACM Gill AC potentiostat was used to measure the OCP of the specimen using a saturated calomel electrode (SEC) as the reference electrode. 
Every dry sliding wear and tribocorrosion test was duplicated and the results from two tests were consistent. After the tests, the wear and corrosion-wear tracks were examined under optical and scanning electron microscopes. The cross-sectional profiles of the wear tracks were measured by a stylus profilometer (Mitutoyo SJ-400) to assess the actual depth and width of the tracks and the amount of material removal. The measured total material removal (TMR) in volume was then divided by the total sliding distance and the applied contact load to obtain the specific total material removal rate in $\mathrm{mm}^{3} \mathrm{~N}^{-1} \mathrm{~m}^{-1}$. A ball crater about $1 \mathrm{~mm}$ diameter was then made on the wear track by rotating a $25.4 \mathrm{~mm}$ diameter bearing steel ball to reveal the actual wear depth and the deformation and cracking behaviour beneath the wear surface, as highlighted in Fig. 1 for the scratch on the oxidised surface.

\section{Results and Discussion}

\subsection{Structural characteristics}

Fig. 2 shows the cross-sections of the thermally oxidised (TO) Ti and Zr specimens and Table 1 summarises the characteristics of the untreated and TO specimens. In consistency with the observations of other investigators (Aniolek et al., 2016; Leto et al., 2014), TO produced a dark oxide layer (OL) at the surface and an oxygen diffusion zone (ODZ) at the subsurface of both materials (Fig. 2). After the TO treatment, the originally polished surface was slightly roughened, with the $\mathrm{R}_{\mathrm{a}}$ value increased from about $0.03 \mu \mathrm{m}$ to about $0.05 \mu \mathrm{m}$ for both TO specimens (Table 1). This could be due to the anisotropic growth of the oxide layer in different grain orientations. Another observation lies in that the mass gain during TO by $\mathrm{Zr}$ was 4 times larger than that by Ti, see Table 1 . This suggests that under the present TO conditions, 4 times more oxygen was incorporated into the surface region of $\mathrm{Zr}$ than into $\mathrm{Ti}$. The greater oxygen uptake by $\mathrm{Zr}$ was confirmed by microscopic examination of the crosssections of the TO specimens, shown in Fig. 2. A much thicker OL was formed on $\mathrm{Zr}$ than on $\mathrm{Ti}$ under the same TO condition. The OL formed on $\mathrm{Zr}$ was $6.3 \mu \mathrm{m}$ thick, while that on $\mathrm{Ti}$ was only $1.1 \mu \mathrm{m}$ thick. However, the oxygen diffusion (ODZ) measured from Fig. 2 was thicker in $\mathrm{Ti}(4.5 \mu \mathrm{m}$, see Table 1) than in $\mathrm{Zr}(2.9 \mu \mathrm{m})$. XRD analysis (Fig. 3) confirmed that the thin OL formed on $\mathrm{Ti}$ was rutile titanium dioxide $\left(\mathrm{R}-\mathrm{TiO}_{2}\right)$, while the thick $\mathrm{OL}$ formed on $\mathrm{Zr}$ was monoclinic zirconium dioxide $\left(\mathrm{m}-\mathrm{ZrO}_{2}\right)$. The diffraction peaks from the substrate $(\alpha-$ Ti and $\alpha-\mathrm{Zr}$ ) were shifted to lower angles as compared to standard peaks due to the dissolution of oxygen in the diffusion zone, which caused expansion of the hexagonal close packed (hcp) lattices. For example, the $\alpha$-Ti (101) and (012) peaks were shifted from $40.20^{\circ}$ 
and $53.03^{\circ}$ to $40.03^{\circ}$ and $52.51^{\circ}$, respectively. The $\alpha-\operatorname{Zr}(101)$ and (012) peaks were shifted from $36.54^{\circ}$ and $48.03^{\circ}$ to $36.32^{\circ}$ and $47.74^{\circ}$, respectively.

Based on the atomic weight of the involved elements ( $\mathrm{Ti}, \mathrm{Zr}$ and $\mathrm{O}$ ), the molar mass of $\mathrm{ZrO}_{2}$ (123.22 $\left.\mathrm{g} \mathrm{mol}^{-1}\right)$ and $\mathrm{TiO}_{2}\left(79.87 \mathrm{~g} \mathrm{~mol}^{-1}\right)$, and the theoretical density of $\mathrm{m}-\mathrm{ZrO}_{2}\left(5.68 \mathrm{~g} \mathrm{~cm}^{-3}\right)$ and $\mathrm{R}_{-} \mathrm{TiO}_{2}\left(4.23 \mathrm{~g} \mathrm{~cm}^{-3}\right)$, it can be estimated that it would require $0.93 \mathrm{mg} \mathrm{cm}^{-2}$ oxygen uptake to form a dense $\mathrm{m}-\mathrm{ZrO}_{2}$ layer of $6.3 \mu \mathrm{m}$ thick on $\mathrm{Zr}$ and $0.19 \mathrm{mg} \mathrm{cm}^{-2}$ oxygen uptake to form a dense $\mathrm{R}-\mathrm{TiO}_{2}$ layer of $1.1 \mu \mathrm{m}$ thick on Ti. Subtracting these values from the measured mass gain in Table 1 led to that in the TO-Ti specimen, $0.07 \mathrm{mg} \mathrm{cm}^{-2}$ oxygen uptake during TO diffused into the subsurface to form the diffusion zone, as compared to $0.11 \mathrm{mg} \mathrm{cm}^{-2}$ in the TO-Zr specimen. Thus more oxygen diffused to the subsurface of TO-Zr than to that of TO-Ti. The above analysis was based on the assumption that the weight gain was caused by oxygen only. Nitrogen uptake was not considered because nitrogen is more inert than oxygen and XRD could not detect any nitride formation in the oxidised specimens.

\subsection{Surface hardness and hardness profiles}

As the result of oxygen incorporation in the surface and subsurface regions to form an OL and an ODZ, the surface and subsurface hardness of CP-Ti and CP-Zr were significantly increased. Fig. 4(a) shows the surface hardness as a function of indentation load and Fig. 4(b) shows the hardness profiles measured across the OL and ODZ in the cross section. The measured surface hardness decreased with increasing indentation load (Fig. 4a) due to the increased substrate effect. At the small indentation load of $0.025 \mathrm{~kg}$, the TO-Zr surface exhibited a hardness close to $1400 \mathrm{HV}_{0.025}$, which was higher than the surface hardness of TO-Ti (about $1100 \mathrm{HV}_{0.025}$ ). Under all indentation loads, the $\mathrm{TO}-\mathrm{Zr}$ specimen possessed higher surface hardness and thus better load bearing capacity than the TO-Ti specimen. From the insets in Fig. 4(a), it can also be seen that indentation under high loads (higher than 0.02 $\mathrm{kg}$ ) led to the formation of cracks surrounding the indent, without flaking of the OL. This suggests that both OLs were relatively brittle but had good adhesion with the underlying ODZ. Hardness profile measurements in the cross sections revealed that the TO-Zr specimen possessed higher hardness than the TO-Ti specimen at all measurement depths, see Fig. 4(b). The better hardening effect in TO-Zr can be explained by the greater oxygen uptake and the resultant thicker OL. 


\subsection{Scratch resistance}

Fig. 5 shows the variation of scratch width with applied scratch load for TO-Ti and TO-Zr. At all scratch loads, the scratch width on TO-Zr was smaller than that on TO-Ti. Thus TO-Zr had better scratch resistance than TO-Ti.

Typical microscopic images of the scratches on TO-Ti are given in Fig. 6, from which it can be seen that cracks started to form both inside and outside the scratch at a scratch load as low as $4 \mathrm{~N}$. The cracks inside the scratch were nearly perpendicular to the scratch direction and were the result of the tensile stresses caused by the tangential traction of the stylus (Holmberg et al., 2003), while the cracks outside the scratch had a chevron shape and were most likely caused by the bending of the OL due to plastic deformation inside the scratch (Xie and Hawthorne, 2001). When the scratch load was increased to $7 \mathrm{~N}$, cracking of the OL inside the scratch became more serious and spallation or flaking of the OL occurred at the edges of the scratch. Cracking and edge spallation of the OL became more severe when the scratch load was further increased to $10 \mathrm{~N}$ and above. Thus, the critical load for the $\mathrm{TiO}_{2}$ layer failure was $7 \mathrm{~N}$.

Fig. 7 shows the scratches on the TO-Zr specimen, together with zoom-in view of the ball craters made on the scratches to reveal the OL and the substrate beneath each scratch. It can be clearly seen that at $10 \mathrm{~N}$ scratch load (Fig. 7a), the OL in the scratch was plastically deformed into the substrate. Despite such a significant plastic deformation, no adhesive failure such as debonding and flaking of the OL was observed. The plastic deformation of the OL inside the scratch caused the bending of the OL at the edges of the scratch and thus the formation of the chevron type cracks. When the scratch load was increased to $15 \mathrm{~N}$ and $20 \mathrm{~N}$ (Fig. 7b), the OL inside the scratch was deformed further into the substrate without layer detachment. However, at the edges of the scratch, in association with the chevron type cracks, chipping of the OL layer was observed. The depth of such chippings was approximately at the OL-ODZ interfacial region, thus demonstrating the adhesive failure nature. At further higher scratch loads, $25 \mathrm{~N}$ and $30 \mathrm{~N}$ (Fig. 7c), chipping at the edges became more significant, and at the same time the OL inside the scratch was removed completely. Thus, the critical load for adhesive failure of the $\mathrm{ZrO}_{2}$ layer was $15 \mathrm{~N}$, which was much larger than $7 \mathrm{~N}$ measured for the $\mathrm{TiO}_{2}$ layer. More importantly, the results shown in Fig. 7 demonstrate that the $\mathrm{ZrO}_{2}$ layer had the ability to accommodate severe plastic deformation without adhesive failure (Fig. 7a). 
The good integrity of the $\mathrm{ZrO}_{2}$ layer with the underlying ODZ can be explained by the variation of stoichiometry and oxygen vacancies with depth from the surface in the $\mathrm{ZrO}_{2}$ layer. Leto et al. (2014) found that in the OL produced on $\mathrm{Zr}-2.5 \% \mathrm{Nb}$ alloy by the commercial Oxinium $^{\mathrm{TM}}$ process, there existed an interfacial region about $1 \mu \mathrm{m}$ thick between the OL and ODZ where a peculiar stoichiometric balance was achieved with a diffuse-type oxygen concentration. This would help to relieve the residual stresses arising from the thermal expansion mismatch between the surface ceramic OL and the metallic ODZ, and thus would contribute to enhanced integrity of the OL.

\subsection{Dry sliding wear behaviour}

During dry sliding, a transition in friction and wear behaviour was observed above certain critical loads for the TO-Ti and TO-Zr specimens. Fig. 8 shows the recorded coefficient of friction $(\mathrm{COF})$ curves for the two specimens at various contact loads. At a small contact load of $1 \mathrm{~N}$, both specimens behaved similarly and exhibited a smooth frictional behaviour. The COF value gradually increased with sliding time and then reached a stable value between 0.5 and 0.6. Increasing the contact load to $2 \mathrm{~N}$ led to an increase in COF values but did not change the generally smooth frictional behaviour of both specimens. Such a smooth frictional behaviour was maintained in the TO-Zr specimen up to the contact load of $10 \mathrm{~N}$ (Fig. 8b). However, for the TO-Ti specimen, when the contact load was increased to $4 \mathrm{~N}$ (Fig. 8a), the frictional behaviour was changed significantly, characterised by the initial smooth regime for the first $600 \mathrm{~s}$ sliding and the sudden change to a fluctuating regime characteristic of the untreated CP-Ti specimen (not shown for clarity purpose). Such a sudden change in friction marked the breakdown of the OL and led to much accelerated wear of the TO-Ti specimen. Fig. 9 shows the morphology and the surface profiles measured across the wear tracks produced on the TO-Ti specimen at $2 \mathrm{~N}$ and $4 \mathrm{~N}$ loads. It can be seen that after dry sliding at $2 \mathrm{~N}$ for $3600 \mathrm{~s}$, the wear depth in the wear track was mostly within the OL thickness and only in some local areas was the OL worn through (Fig. 9a). However, after sliding at the higher contact load of $4 \mathrm{~N}$, the OL and the ODZ were removed completely from the wear track (Fig. 9b). Thus under the present dry sliding conditions, the TO-Ti specimen can only resist up to a contact load of $2 \mathrm{~N}$ without serious OL and ODZ breakdown.

On the other hand, the TO-Zr specimen can resist a much higher contact load without OL and ODZ breakdown, as shown in Fig. 8(b) and Fig. 10(a). For the TO-Zr specimen, a sudden change in frictional behaviour occurred during sliding at $15 \mathrm{~N}$ load, as compared to $4 \mathrm{~N}$ for 
the TO-Ti specimen (Fig. 8). As shown in Fig. 10(b), such a sudden change in frictional behaviour was also related to the breakdown of the OL and ODZ, leading to much accelerated wear of the TO-Zr specimen. Clearly, under the present dry sliding conditions, the TO-Zr specimen possessed a load bearing capacity that was at least 5 times larger than that of the TO-Ti specimen.

The measured total material removal (TMR) rate from the wear track as a function of contact load is given in Fig. 11(a). Since a nearly circular wear scar was produced on the counterface alumina ball, the mean diameter of the wear scar was measured and presented in Fig. 11(b) as a function of contact load. For comparison purpose, untreated raw $\mathrm{Ti}$ and $\mathrm{Zr}$ specimens were also tested at low contact loads and the results are also shown in Fig. 11. It can be seen that wear from the specimen and from the alumina ball followed the same trend as contact load was increased. A larger TMR rate from the wear track corresponded to a larger wear scar on the ball due to the increased contact area. As compared to the untreated specimens, TO effectively reduced the TMR rate at the small contact load of $1 \mathrm{~N}$ by more than two orders of magnitude (Fig. 11a). As long as the OL maintained its integrity with the substrate, TO-Ti and TO-Zr behaved similarly in terms of wear resistance. However, with increasing load from $1 \mathrm{~N}$ to $4 \mathrm{~N}$, the TMR rate from the TO-Ti specimen increased steeply due to the wearing through and breakdown of the OL and the ODZ. At further higher contact loads, the substrate dominated the wear process because the OL and ODZ were worn through during the early stage of sliding. On the other hand, the TO-Zr specimen maintained a very small TMR rate up to the contact load $10 \mathrm{~N}$, above which the TMR rate increased abruptly due to the breakdown of the OL and ODZ. Thus, TO-Zr possessed much better wear resistance at high contact loads than TO-Ti.

Fig. 12 shows typical SEM images taken from the wear tracks on TO-Ti ((a) and (b)) and TO-Zr ((c) and (d)). Fig. 12(a) shows that at $2 \mathrm{~N}$, the OL on the TO-Ti specimen was worn smoothly and the ODZ was exposed at the centre of the wear track, in agreement with the observation and measurement in Fig. 9. At 4 N, the OL on TO-Ti suffered from severe flaking at the edges of the wear track and wear mainly occurred in the substrate (Fig. 12b). Flaking of the OL led to the observed sudden change in friction shown in Fig. 8(a). As mentioned earlier, no OL breakdown occurred in the TO-Zr specimen at contact loads below 15 N. Fig. 12(c) and (d) show that at contact loads below this critical load, wear of the OL was caused by micro abrasion, microcracking and delamination within the thick OL. The 
wear track surface was populated with microcracks (Fig. 12d). The linkage of these microcracks led to the formation of wear debris, leaving behind some shallow craters on the worn surface. The depths of these craters, shown in Fig 12(c) and (d), were very small, within the OL. Fig. 13 shows a wear crater caused by the cohesive failure of the OL and the results of EDS spot elemental analysis inside and outside the crater. The results showed that inside the crater, the chemical composition was near stoichiometric $\mathrm{ZrO}_{2}$, thus confirming that the crater depth was shallower than the OL thickness and the failure was cohesive. Outside the crater, some $\mathrm{Al}$ and $\mathrm{C}$ were detected, indicating material transfer from the alumina ball and contamination of the real contact areas from the environment.

\subsection{Tribocorrosion behaviour}

During tribocorrosion testing in Ringer's solution at $37^{\circ} \mathrm{C}$ at open circuit without externally applied potential, attempts were made to measure and record the evolution of open circuit potential (OCP) continuously. Fig. 14(a) shows the recorded OCP curves for the untreated (raw) $\mathrm{Ti}$ and TO-Ti specimens. Since $\mathrm{R}-\mathrm{TiO}_{2}$ is a semiconductor and the OL on TO-Ti was thin, OCP could be measured before, during and after sliding. However, difficulties were encountered in measuring the $\mathrm{OCP}$ of the $\mathrm{TO}-\mathrm{Zr}$ specimen due to the poor conductivity of the dense and thick $\mathrm{m}-\mathrm{ZrO}_{2}$ layer which is a barrier layer. The measured OCP of the TO-Zr specimen varied largely between $0 \mathrm{mV}$ (SCE) and $2000 \mathrm{mV}$ (SCE) without a stable value, as can be seen from the large spike in Fig. 14(b) for the first $300 \mathrm{~s}$ measurement without sliding.

From Fig. 14(a), it can be seen that for the untreated Ti specimen, sliding led to a significant drop in OCP due to the destruction or removal of the passive film by the mechanical sliding action. This is a common phenomenon observed for passive metals by many investigators (Ponthiaux et al., 2004; Dearnley and Aldrich-Smith, 2004; Jiang et al. 2002; Sun and Rana, 2011). The drop in OCP during sliding increased with increasing contact load, presumably due to the increased mechanical damage and the increased wear track area (Mischler, 2008; Landolt et al. 2001). Sliding of the TO-Ti specimen at a small contact load $1 \mathrm{~N}$ did not lead a significant change in OCP, Fig. 14(a). Thus the wear track was in a passive state during sliding at $1 \mathrm{~N}$ load. This is because the OL maintained its integrity with the substrate, as confirmed by wear track profile measurements and microscopic examination. It is interesting to note that during sliding of TO-Ti at $2 \mathrm{~N}$ load, the OCP initially followed a similar trend to that at $1 \mathrm{~N}$ load, but experienced a significant drop after about $3000 \mathrm{~s}$ to gradually reach OCP 
values characteristic of the untreated $\mathrm{Ti}$ in the activated state. Such a significant drop in OCP was also observed at higher contact loads of $4 \mathrm{~N}$ and $10 \mathrm{~N}$, Fig. 14(a). The time at which OCP started to drop decreased with increasing contact load. Fig. 15(a) shows the crosssectional profiles of the wear tracks on TO-Ti. The OL in the $2 \mathrm{~N}$ wear track was just worn through in the central region, leading to the exposure of the ODZ. Microscopic examination showed that in the central region of the $2 \mathrm{~N}$ wear track, only patches of the OL remained and in many areas the ODZ was exposed. Sliding at the higher contact load of $4 \mathrm{~N}$ led to the complete removal of the OL, but the wear depth was confined within the ODZ (Fig. 15(a)). At the further higher contact load of $10 \mathrm{~N}$, the OL and ODZ were removed completely from the wear track, leading to the exposure of the substrate (Fig. 15(a)). It is thus clear that the significant drop in OCP of the TO-Ti specimen during sliding at contact loads $2 \mathrm{~N}$ and above (Fig. 14(a)) was caused by the wearing through of the OL (at $2 \mathrm{~N}$ and $4 \mathrm{~N}$ ) and then wearing through of the ODZ (at $10 \mathrm{~N})$.

Fig. 14(b) shows OCP curves recorded during tribocorrosion of the TO-Zr specimen. For clarity purpose, the OCP curves of the untreated $\mathrm{Zr}$ specimen are not included, which are similar to those of the untreated Ti specimen shown in Fig. 14(a). As mentioned earlier, due to the poor conductivity of the thick $\mathrm{ZrO}_{2}$ layer, it was unrealistic to measure the OCP of the TO-Zr specimen. Indeed, at contact loads of $10 \mathrm{~N}$ and below, the recorded OCP values before, during and after sliding were unstable with large potential spikes. However, when the contact load was increased to $15 \mathrm{~N}$, OCP became measurable after about $600 \mathrm{~s}$ sliding. This suggests that the specimen became conductive after a certain period of sliding. At the further higher contact load of $20 \mathrm{~N}$, the OCP became measurable after a short period of sliding. Fig. 15(b) shows the cross-sectional profiles of the wear tracks on the TO-Zr specimen. The wear tracks were narrow and shallow. At the highest contact load of $20 \mathrm{~N}$ applied, the wear depth was about $1.3 \mu \mathrm{m}$, which was much smaller than the OL thickness. Clearly, the improved conductivity of the TO-Zr specimen at $15 \mathrm{~N}$ and $20 \mathrm{~N}$ loads was not due to the wearingthrough or removal of the non-conducting OL in the wear track. In fact, the OL maintained its integrity with the substrate, as shown in Fig. 16. The wear track produced at $10 \mathrm{~N}$ comprised of many abrasion marks and corrosion products. No cracks were evident in the $10 \mathrm{~N}$ wear track (Fig. 16a). However, in the wear track produced at $15 \mathrm{~N}$, many cracks were observed on the worn surface. Some of these cracks can be seen penetrating through the OL and propagating to the substrate (Fig. 16b). Cracking of the OL and propagation of the cracks to 
the substrate were more obvious at the higher contact load of $20 \mathrm{~N}$ (Fig. 16c). Fig. 16(d) is an SEM image showing more clearly the propagation of cracks from the OL to the substrate. It is thus clear that the improved conductivity of the TO-Zr specimen at high contact loads was due to crack formation in the wear track and the propagation of the cracks to reach the conductive substrate.

Fig. 17 shows the average COF measured during tribocorrosion for the test specimens. Sliding in the Ringer's solution resulted in lower COF than dry sliding due to the lubricating effect of the solution. At low contact loads, TO-Ti exhibited much lower COF than the untreated $\mathrm{Ti}$, demonstrating the friction-reducing effect of the OL. At high contact loads, the breakdown of the OL lead to much increased friction. On the other hand, the TO-Zr specimen maintained relatively low COF at all contact loads because the OL was not removed during sliding. The increase in COF at high contact loads could be related to the formation of cracks in the corrosion-wear track, which can change the real contact area and stress distribution in the contact zone.

The measured TMR rate from the corrosion-wear track and the mean diameter of the wear scar on the alumina ball are given in Fig. 18. As compared to the untreated specimens, TO effectively reduced the TMR rate by 2 to 3 orders of magnitude at small contact loads of $1 \mathrm{~N}$ and $2 \mathrm{~N}$ (Fig. 18(a)). Wear of the counterface alumina ball was also reduced by TO treatment of the specimens (Fig. 18(b)). At higher contact loads, the effectiveness of TO-Ti in reducing TMR rate of Ti was reduced due to the breakdown of the OL and the ODZ. On the other hand, TO-Zr possessed very good resistance to TMR at high contact loads because the OL maintained its integrity with the substrate despite the formation and propagation of cracks. At contact loads above $2 \mathrm{~N}$, the resistance of TO-Zr to TMR caused by tribocorrosion in the Ringer's solution was two orders of magnitude better than that of TO-Ti (Fig. 18(a)).

\section{Conclusions}

The comparative study in this work has unveiled the difference in mechanical behaviour between thermally oxidised $\mathrm{Ti}$ and $\mathrm{Zr}$. The conclusions are as follows.

(1) Under the present thermal oxidation condition, 4 times more oxygen is introduced into $\mathrm{CP}-\mathrm{Zr}$ than into $\mathrm{CP}-\mathrm{Ti}$. As a result, the oxide layer produced on $\mathrm{CP}-\mathrm{Zr}$ is nearly 6 times thicker than that on CP-Ti. 
(2) The TO-Zr possesses higher hardness, a deeper hardening depth and a greater load bearing capacity than the TO-Ti.

(3) The TO-Zr exhibits better scratch resistance than the TO-Ti. During the scratch test, the oxide layer on TO-Ti suffers from edge spallation at a load as small as $7 \mathrm{~N}$, while the oxide layer on $\mathrm{TO}-\mathrm{Zr}$ can resist a scratch load up to $15 \mathrm{~N}$ without adhesive failure. The oxide layer on $\mathrm{TO}-\mathrm{Zr}$ can accommodate severe plastic deformation and maintains good integrity with the substrate at high scratch loads.

(4) Under the present dry sliding conditions, as long as the oxide layer maintains integrity with the substrate, such as at small contact loads, both TO-Ti and TO-Zr specimens show similar wear resistance. However, at high contact loads, the oxide layer on TO-Ti is removed easily, leading to accelerated wear of the TO specimen. On the other hand, the oxide layer on TO-Zr can resist much higher contact loads without breakdown and thus possesses a much higher load bearing capacity and better wear resistance than TO-Ti.

(5) Under tribocorrosion conditions in Ringer's solution, the oxide layer on TO-Ti is removed from the corrosion-wear track at contact load as small as $2 \mathrm{~N}$ and thus loses its barrier nature in the corrosive environment. On the other hand, the oxide layer on TO-Zr maintains its integrity and barrier nature up to a contact load of $10 \mathrm{~N}$ without crack formation and layer breakdown. Although at higher contact loads of $15 \mathrm{~N}$ and above, the oxide layer on TO-Zr still maintains its integrity with the substrate during tribocorrosion, cracks form in the oxide layer and penetrate through the oxide layer to reach the substrate, thus losing the barrier nature of the oxide layer against corrosion.

\section{Acknowledgements}

One of the authors (AA) would like to thank the Saudi Cultural Bureau in London for proving a $\mathrm{PhD}$ scholarship to facilitate this research. 


\section{References}

Alansari, A., Sun, Y., 2017. Effect of oxidation time on the tribological behaviour of thermally oxidized commercially pure zirconium under dry sliding conditions. Surf. Coat. Technol. 309, 195-202.

Aniolek, K., Kupka, M., Barylski, A., 2016. Sliding wear resistance of oxide layers formed on a titanium surface during thermal oxidation. Wear 356-357, 23-29.

Bailey, R., Sun, Y., 2013. Unlubricated sliding friction and wear characteristics of thermally oxidized commercially pure titanium. Wear 308, 61-70.

Bell, T., Dong, H., Sun, Y., 1998. Realising the potential of duplex surface engineering. Trib. Int. 3, 127-137.

Biswas, A., Majumdar, J.D., 2009. Surface characterization and mechanical property evaluation of thermally oxidized Ti-6Al-4V. Materials Characterization 60, 513-518.

Bloyce, A., 1998. Surface engineering of titanium alloys for wear protection. Proc. IMechE Part J: J. Engng Tribol. 212, 467-476.

Bloyce, A., Qi, P.Y., Dong, H., Bell, T., 1998. Surface modification of titanium alloys for combined improvements in corrosion and wear resistance. Surf. Coat. Tech. 107,125-132.

Byeli, A.V., Kukareko, V.A., Kononov, A.G., 2012. Titanium and zirconium based alloys modified by intensive plastic deformation and nitrogen ion implantation for biocompatible implants. J. Mech. Behav. Biomed. Mater. 6, 89-94.

Chevalier, J., 2006. What future for zirconia as a biomaterial?. Biomaterials 27, 535-543.

Dearnley, P.A., Aldrich-Smith, G., 2004. Corrosion-wear mechanisms of hard coated austenitic 316L stainless steel. Wear 256, 491-499.

Dong, H., Bell, T., 1999. Designer surfaces for titanium components. Anti Corrosion Methods Mater. 46, 338-345.

Galetz, M.C., Fleischmann, E.W., Konrad, C.H., Schuetz, A., Glatzel, U., 2010. Abrasion resistance of oxidized zirconium in comparison with CoCrMo and titanium nitride coatings for artificial knee joints. J Biomed Mater Res B: Appl Biomater. 93B, 244-251.

Gepreel, M.A.H., Niinomi, M., 2013. Biocompatibility of Ti-alloys for long-term implantation. J. Mech. Behav. Biomed. Mater. 20, 407-415.

Good, V., Widding, K., Hunter, G., Heuer, D., 2005. Oxidized zirconium: a potentially longer lasting hip implant. Mater. Des. 26, 618-622.

Guleryuz, H., Cimenoglu, H., 2004. Effect of thermal oxidation on corrosion and corrosionwear behaviour of a Ti-6Al-4V alloy. Biomaterials 25, 3325-3333. 
Haygarth, J.C., Fenwick, L.J., 1984. Improved wear resistance of zirconium by enhanced oxide films. Thin Solid Films 118, 351-362.

Holmberg, K., Laukkanen, A., Ronkainen, H., Wallin, K., Varjus, S., 2003. A model for stresses, crack generation and facture toughness calculation in scratched TiN-coated steel surfaces. Wear 254, 278-291.

Hunter, G., Asgian, C.M., Hines, G.I., 2002. Methods of surface hardening zirconium alloys and resulting products. United States Patent, US 6447550, 2002.

Innocenti, M., Matassi, F., Carulli, C., Nistri, L., Civinini, R., 2014. Oxidized zirconium femoral component for TKA: a follow-up note of a previous report at a minimum 10 years. The Knee 21, 858-861.

Ji, R., Li, X.Y., H. Dong, H., 2010. Ceramic conversion treatment of zirconium alloys to combat wear. Suf. Eng. 26, 30-36.

Jiang, J., Stack, M.M., Neville, A., 2002. Modelling the tribo-corrosion interaction in aqueous sliding conditions. Trib. Int. 35, 669-679.

Krishna, D.S.R., Brama, Y.L., Sun, Y., 2007. Thick rutile layer on titanium for tribological applications. Trib. Int. 40, 329-334.

Kumar, S., Narayana, S., Raman, S., Seshadri, S.K., 2010. Thermal oxidation of Ti6Al4V alloy: Microstructural and electrochemical characterization. Materials Chemistry and Physics 119, 337-346.

Landolt, D., Mischler, S., Stemp, M., 2001. Electrochemical methods in tribocorrosion: a critical appraisal. Electrochimica Acta 46, 3913-3929.

Leto, A., Zhu, W., Matrubara, M., Pezzotti, G., 2014. Bioinertness and fracture toughness evaluation of the monoclinic zirconia surface film of Oxinium ${ }^{\mathrm{TM}}$ femoral head by Raman and cathodoluminescence spectroscopy. J. Mech. Behav. Biomed. Mater. 31, 135-144.

Lieblich, M., Barriuso, S., Multigner M., Gonzalez-Doncel, G., 2016. Thermal oxidation of medical Ti6Al4V blasted with ceramic particles: Effects on the microstructure, residual stresses and mechanical properties. J. Mech. Behav. Biomed. Mater. 54, 173-184.

Liu, Z., Welsch, G., 1988. Literature survey on diffusivities of oxygen, aluminium, and vanadium in alpha titanium, beta titanium, and in rutile. Metall. Trans. A19, 1121-1125.

Ma, X., Toffolon-Masclet, C., Guilbert, T., Hamon, D., Brachet, J.C., 2008. Oxidation kinetics and oxygen diffusion in low-tin Zircaloy-4 up to 1523 K. J. Nuclear Mater. 377, 359-369. 
Maekawa, T., Ishii, B., 1962. Oxidation of zirconium in air, Tans JIM 3, 203-209.

S. Mischler, S., 2008. Triboelectrochemical techniques and interpretation methods in tribocorrosion: a comparative evaluation. Trib. Int. 41, 573-583.

M. Niinomi, M., 2002. Recent metallic materials for biomedical applications.

Metall. Mater. Trans. A 33, 477-486.

Patel, A.M., Spector, M., 1997. Tribological evaluation of oxidized zirconium using an articular cartilage counterface: a novel material for potential use in hemiarthroplasty. Biomaterials 18, 441-447.

Pawar, V., Weaver, C., Jani, S., 2011. Physical characterization of a new composition of oxidized zirconium- $2.5 \mathrm{wt} \%$ niobium produced using a two step process for biomedical applications. App. Suf. Sci. 257, 6118-6124.

Ploc, R.A., 1980. An electron microscope study of breakaway oxidation of zirconium at 623 K. J. Nucl. Mater. 91, 322-328.

Ponthiaux, P., Wenger, F., Drees, D., Celis, J.P., 2004. Electrochemical techniques for studying tribocorrosion processes. Wear 256, 459-468.

Sun, Q., Hu, T., Fan, H., Zhang, Y., Hua, L., 2016. Thermal oxidation behaviour and tribological properties of textured TC4 surface: Influence of thermal oxidation temperature and time. Trib. Int. 94, 479-489.

Sun, Y., Rana, V., 2011. Tribocorrosion behaviour of AISI 304 stainless steel in $0.5 \mathrm{M} \mathrm{NaCl}$ solution. Mater. Chem. Phys. 129, 138-147.

Wallwork, G.R., Rosa, C.J., Smeltzer, W.W., 1965. Breakaway phenomena in the oxidation of zirconium at 850 and $950{ }^{\circ} \mathrm{C}$. Corros. Sci., 113-120.

Wang, S., Liao, Z., Liu, Y., Liu, W., 2014a. Influence of thermal oxidation temperature on the microstructural and tribological behavior of Ti6Al4V alloy. Surf. Coat. Technol. 240, 470-477.

Wang, S., Liu, Y., Zhang, C., Liao, Z., W Liu, W., 2014b. The improvement of wettability, biotribological behavior and corrosion resistance of titanium alloy pretreated by thermal oxidation. Tribology International 79, 174-182.

Xie, Y., Hawthorne, H.M., 2001. A model for compressive coating stresses in the scratch adhesion test. Surf. Coat. Technol. 141, 15-25.

Yamamoto, O., Alvarez, K., Kikuchi, T., Fukuda, M., 2009. Fabrication and characterization of oxygen-diffused titanium for biomedical applications. Acta Biomaterialia 5, 3605-3615. 


\section{List of figure captions:}

Fig. 1: A typical scratch on the TO-Zr surface and a ball crater made on the scratch to provide an enlarged view of the OL and the material deformation behavior beneath the scratch (arrowed).

Fig. 2: Microscopic images showing the cross-sectional morphology of the (a) TO-Ti and (b) TO-Zr specimens produced at $650{ }^{\circ} \mathrm{C}$ for $6 \mathrm{~h}$.

Fig. 3: X-ray diffraction patterns generated from the TO-Ti and TO-Zr specimens.

Fig. 4: Surface hardness of the TO-Ti and TO-Zr specimens as a function of indentation load (a) and microhardness profiles measured across the oxidised layers (b). The insets show the hardness indents made on the surface (a) and in the subsurface (b). The hardness indents shown in (b) are for illustration only. In actual measurements, the distance between two indents was more than three times of the indent size.

Fig. 5: Scratch width as a function of scratch load for the TO-Ti and TO-Zr specimens.

Fig. 6: Microscopic images showing the scratches made on the TO-Ti surface at various scratch loads. Arrow indicates the scratch direction.

Fig. 7: Microscopic images showing the zoom-in view of ball craters on scratches made on the TO-Zr surface at various scratch loads.

Fig. 8: COF curves recorded during dry sliding of the TO-Ti (a) and TO-Zr (b) specimens under various contact loads.

Fig. 9: Three dimensional view of the wear tracks and the measured surface profiles across the tracks produced by dry sliding of the TO-Ti at (a) $2 \mathrm{~N}$ and (b) $4 \mathrm{~N}$.

Fig. 10: Three dimensional view of the wear tracks and the measured surface profiles across the tracks produced by dry sliding of the TO-Zr at (a) $10 \mathrm{~N}$ and (b) $15 \mathrm{~N}$.

Fig. 11: Measured total material removal (TMR) rate from the wear track (a) and ball wear scar diameter (b) for the TO-Ti and TO-Zr specimens under various contact loads.

Fig. 12: SEM images showing the morphology of the wear tracks produced on the TO-Ti (a and $b$ ) and $\mathrm{TO}-\mathrm{Zr}$ (c and d) specimens during dry sliding under various contact loads.

Fig. 13: SEM image and EDS elemental spot analysis in area 1 and 2 of the wear track produced on the TO-Zr specimen during dry sliding under $4 \mathrm{~N}$ load.

Fig. 14: Open circuit potential (OCP) recorded before, during and after sliding of the untreated Ti and TO-Ti (a) and TO-Zr (b) specimens, in Ringer's solution at $37^{\circ} \mathrm{C}$.

Fig. 15: Typical cross-sectional profiles of the wear tracks produced on the TO-Ti (a) and TO-Zr (b) specimens during tribocorrosion under various contact loads.

Fig. 16: Microscopic images of the zoom-in view of ball craters made on the wear tracks produced on the TO-Zr specimen during tribocorrosion in Ringer's solution at $37{ }^{\circ} \mathrm{C}$ under (a) $10 \mathrm{~N}$, (b) $15 \mathrm{~N}$, (c) and (d) $20 \mathrm{~N}$ contact loads, showing the wear tracks, the OL and substrate beneath each wear track. Arrows show the penetration of cracks in the substrate. 
Fig. 17: Measured average coefficient of friction for the test specimens under tribocorrosion conditions.

Fig. 18: Measured total material removal (TMR) rate from the corrosion wear track (a) and ball wear scar diameter (b) for the TO-Ti and TO-Zr specimens under tribocorrosion conditions. 


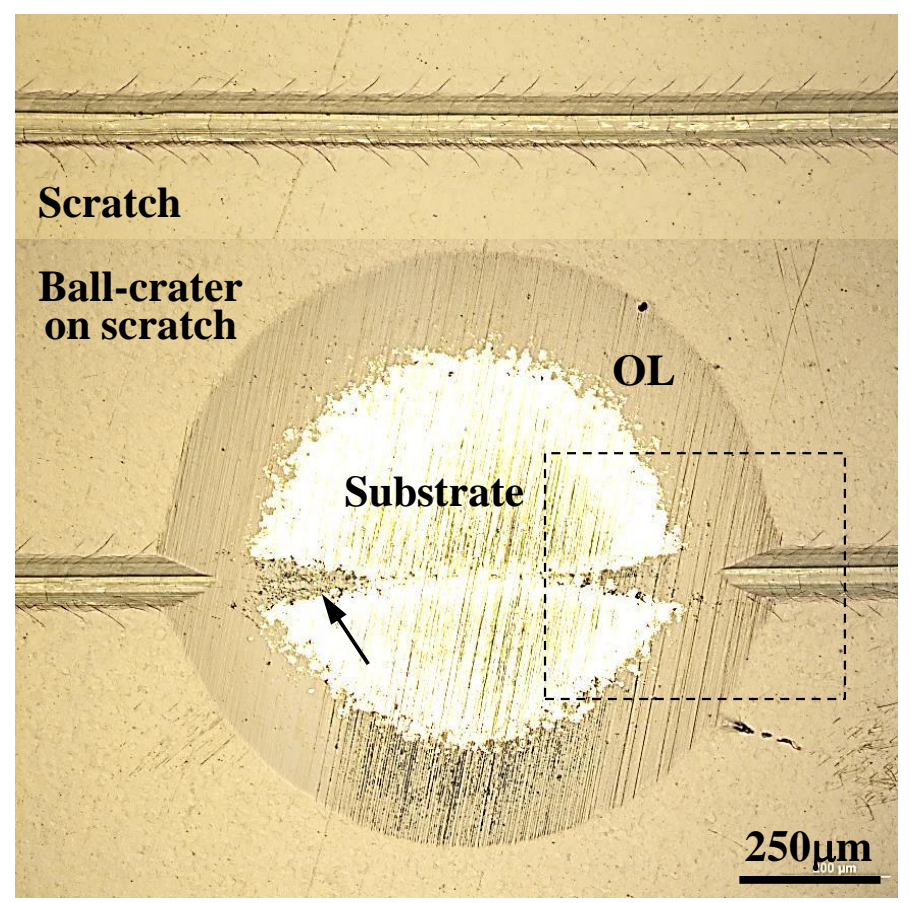

Fig. 1: A typical scratch on the TO-Zr surface and a ball crater made on the scratch to provide an enlarged view of the OL and the material deformation behavior beneath the scratch (arrowed). 




Fig. 2: Microscopic images showing the cross-sectional morphology of the (a) TO-Ti and (b) TO-Zr specimens produced at $650{ }^{\circ} \mathrm{C}$ for $6 \mathrm{~h}$. 


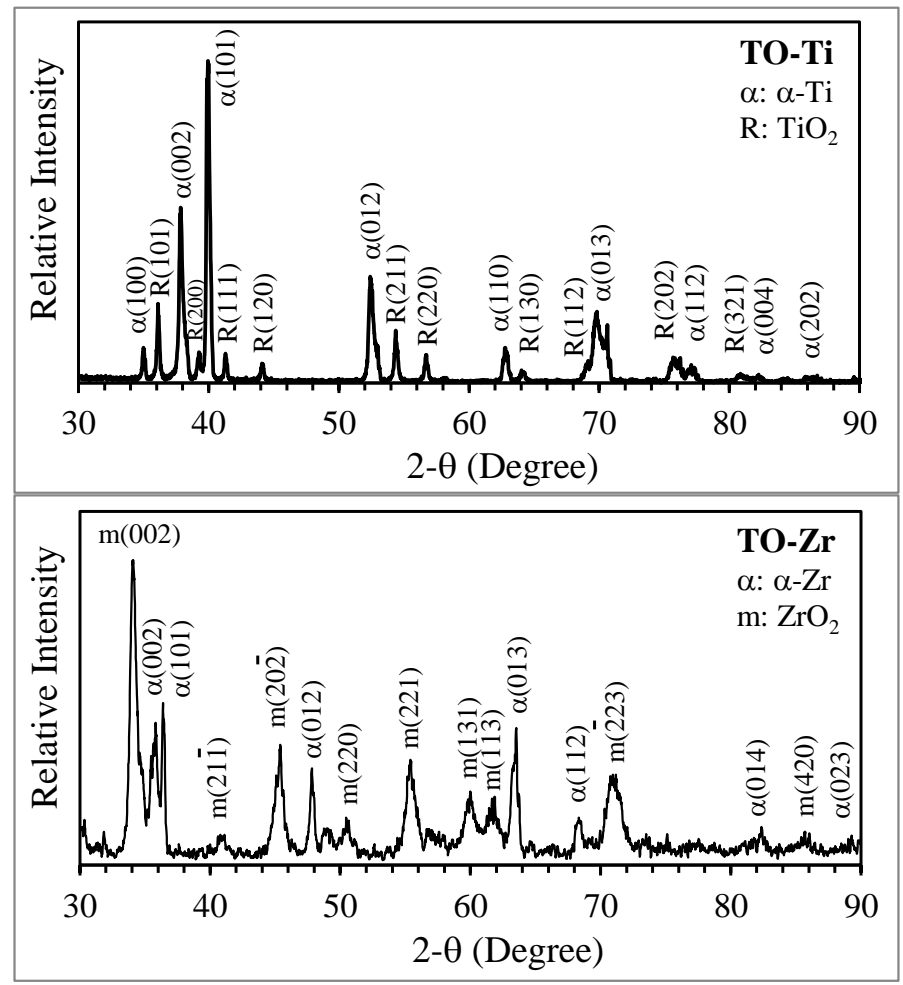

Fig. 3: X-ray diffraction patterns generated from the TO-Ti and TO-Zr specimens. 



Fig. 4: Surface hardness of the TO-Ti and TO-Zr specimens as a function of indentation load (a) and microhardness profiles measured across the oxidised layers (b). The insets show the hardness indents made on the surface (a) and in the subsurface (b). The hardness indents shown in (b) are for illustration only. In actual measurements, the distance between two indents was more than three times of the indent size. 


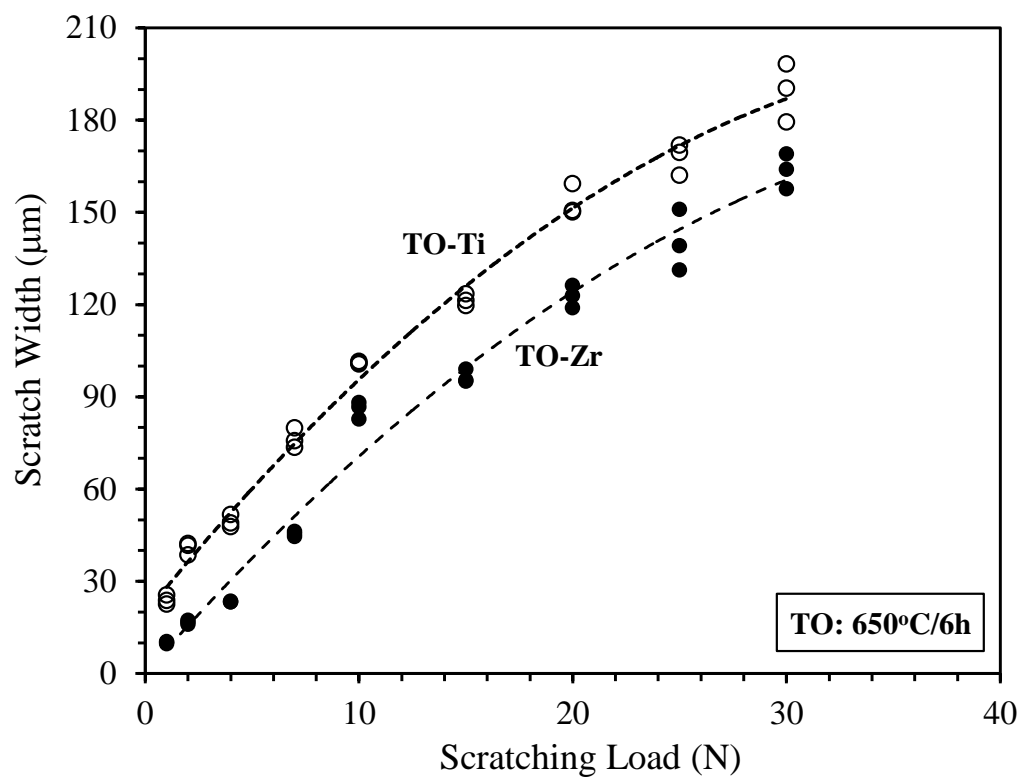

Fig. 5: Scratch width as a function of scratch load for the TO-Ti and TO-Zr specimens. 



Fig. 6: Microscopic images showing the scratches made on the TO-Ti surface at various scratch loads. Arrow indicates the scratch direction. 

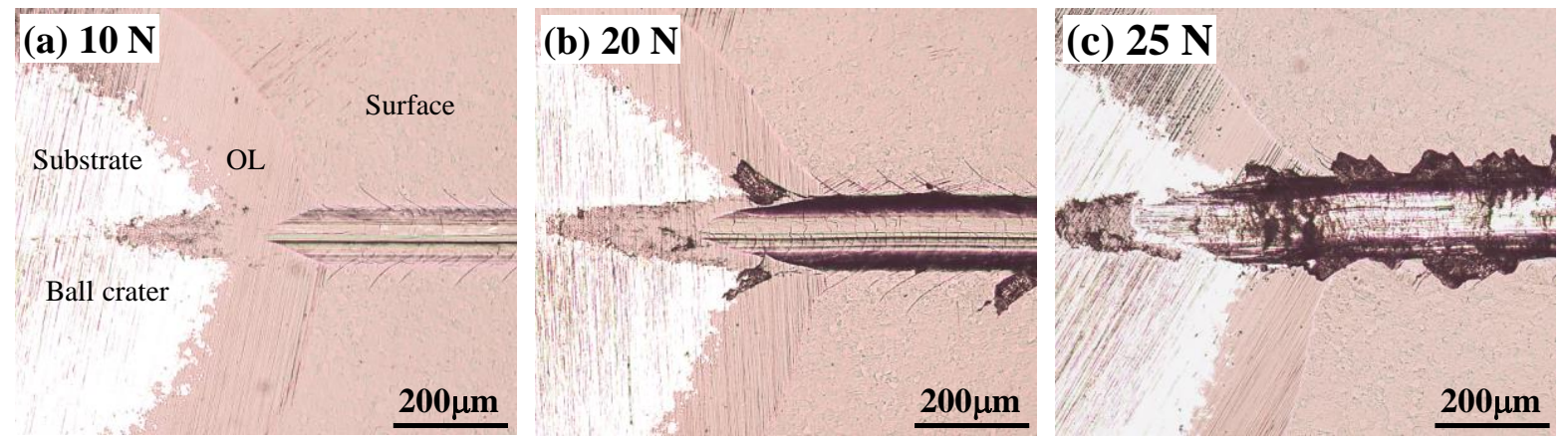

Fig. 7: Microscopic images showing the zoom-in view of ball craters on scratches made on the TO-Zr surface at various scratch loads. 

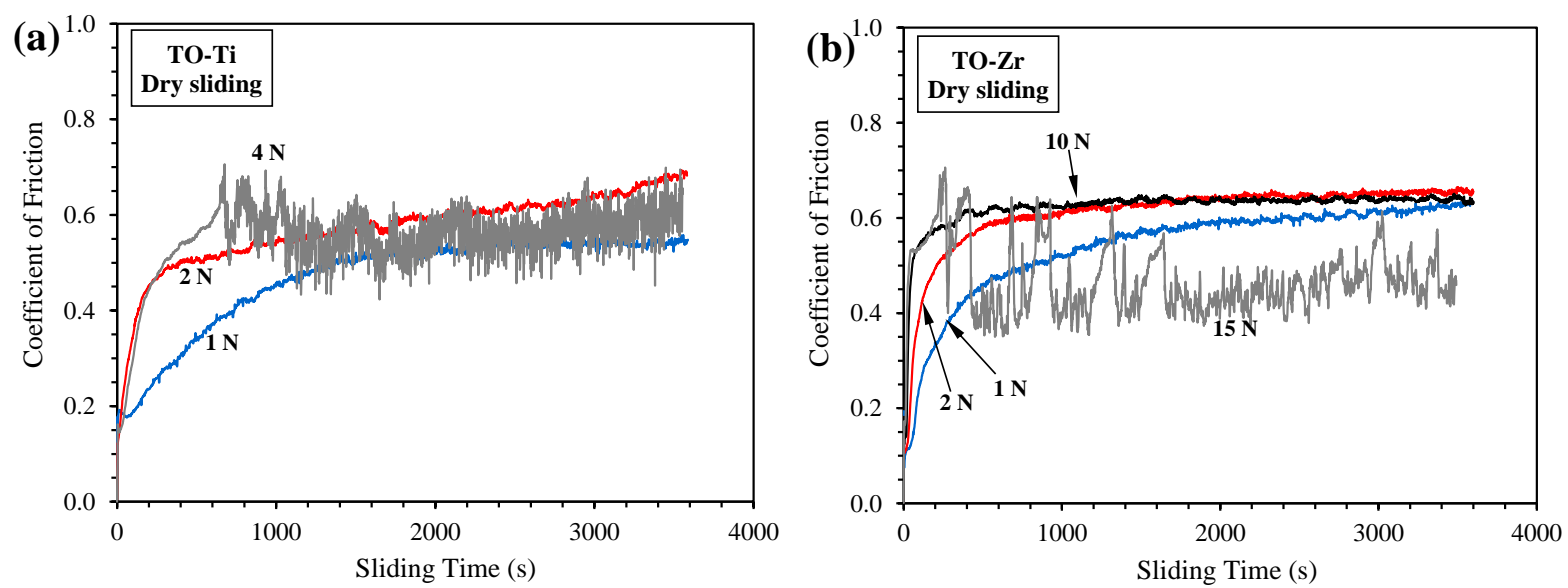

Fig. 8: COF curves recorded during dry sliding of the TO-Ti (a) and $\mathrm{TO}-\mathrm{Zr}$ (b) specimens under various contact loads. 



Fig. 9: Three dimensional view of the wear tracks and the measured surface profiles across the tracks produced by dry sliding of the TO-Ti at (a) $2 \mathrm{~N}$ and (b) $4 \mathrm{~N}$. 

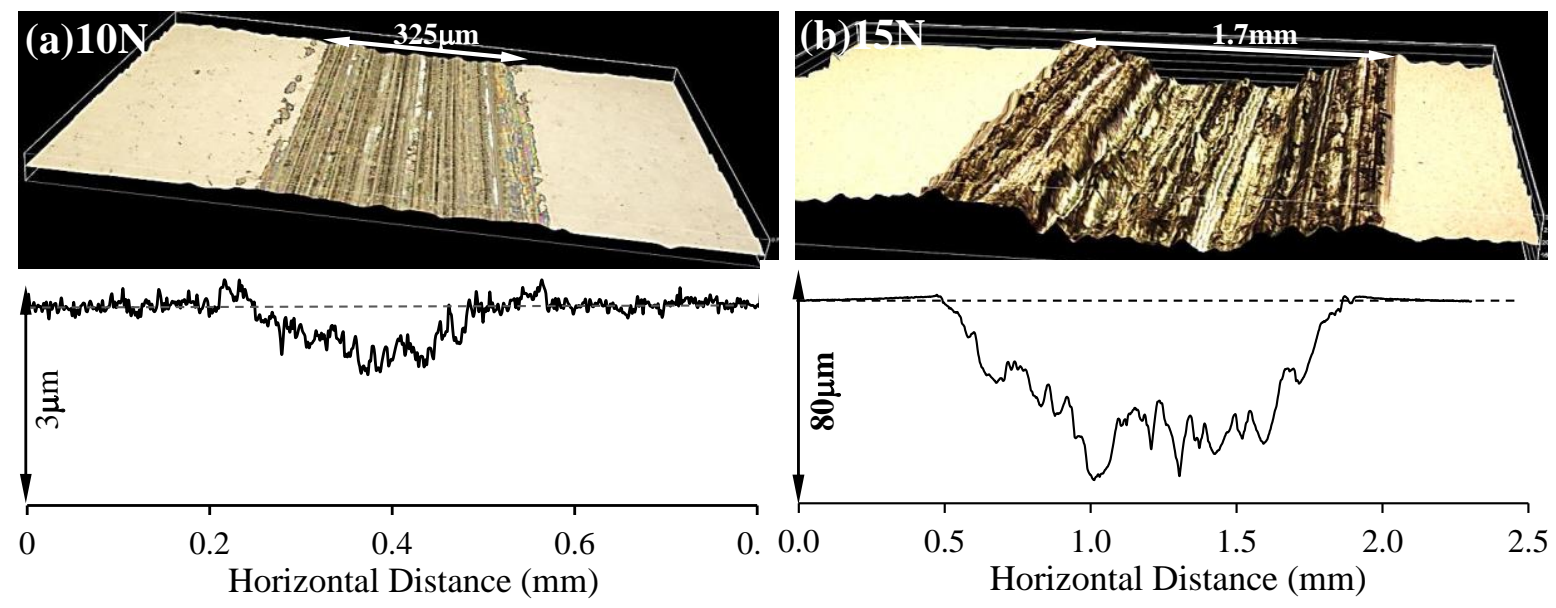

Fig. 10: Three dimensional view of the wear tracks and the measured surface profiles across the tracks produced by dry sliding of the TO-Zr at (a) $10 \mathrm{~N}$ and (b) $15 \mathrm{~N}$. 

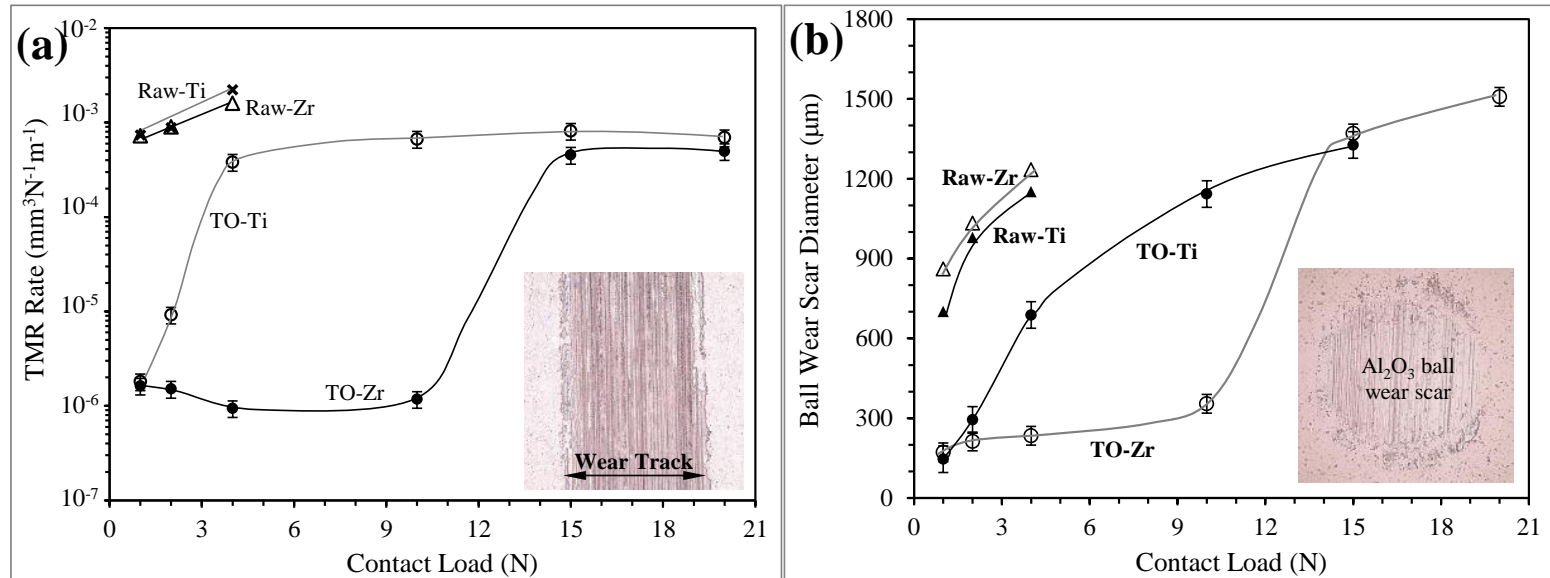

Fig. 11: Measured total material removal (TMR) rate from the wear track (a) and ball wear scar diameter (b) for the TO-Ti and TO-Zr specimens under various contact loads. 



Fig. 12: SEM images showing the morphology of the wear tracks produced on the TO-Ti (a and $b$ ) and $\mathrm{TO}-\mathrm{Zr}$ (c and d) specimens during dry sliding under various contact loads. 


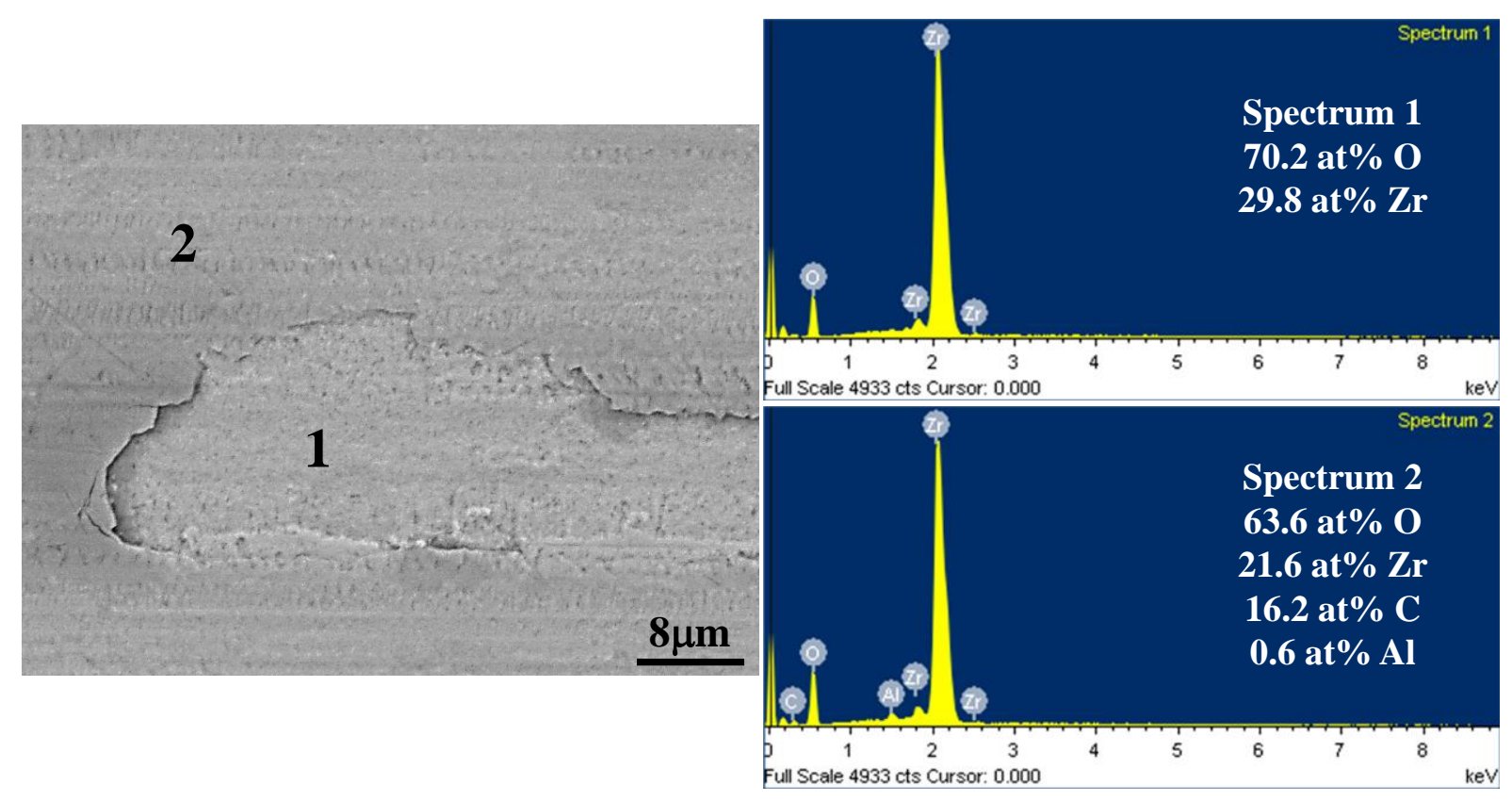

Fig. 13: SEM image and EDS elemental spot analysis in area 1 and 2 of the wear track produced on the TO-Zr specimen during dry sliding under $4 \mathrm{~N}$ load. 

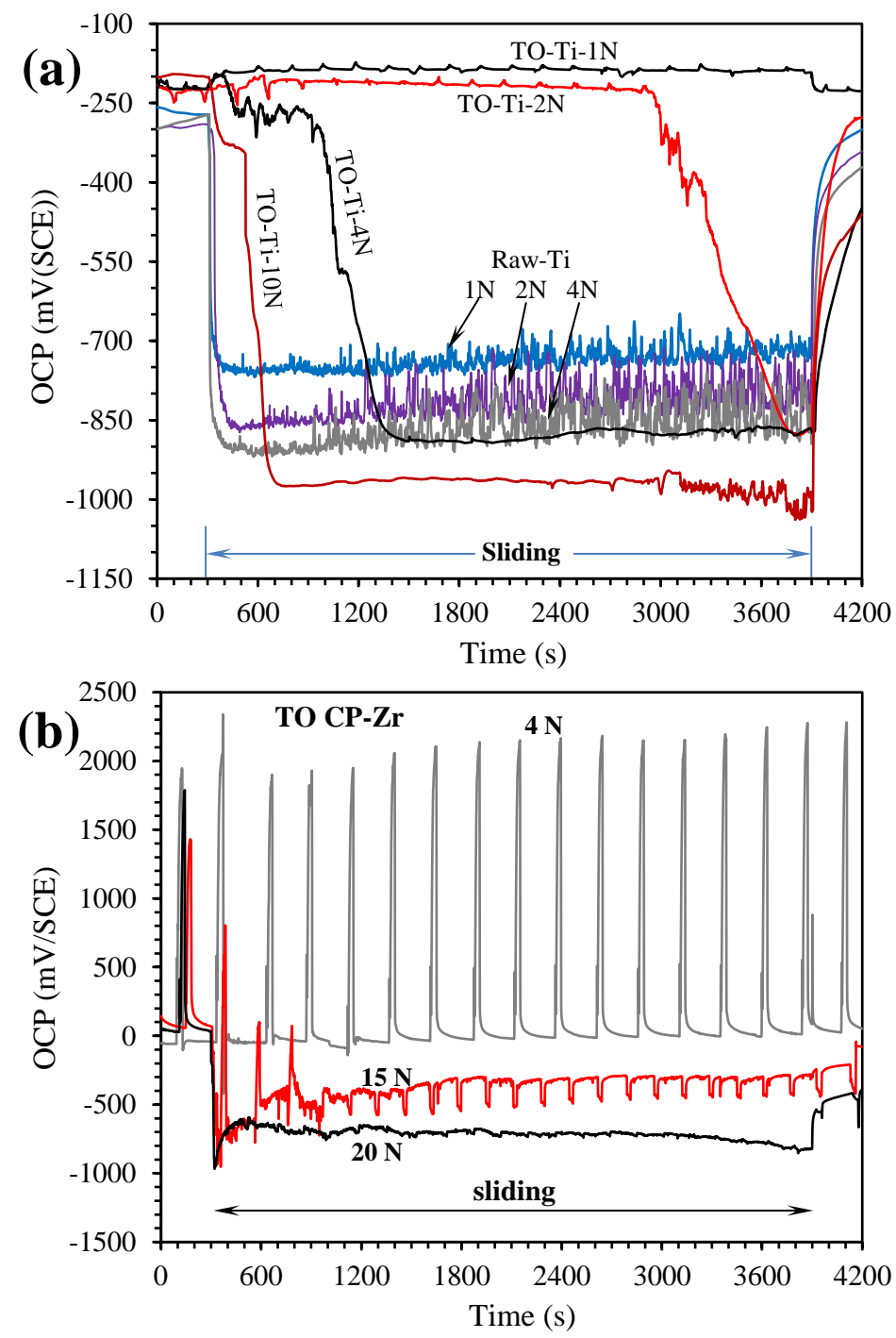

Fig. 14: Open circuit potential (OCP) recorded before, during and after sliding of the untreated Ti and $\mathrm{TO}-\mathrm{Ti}$ (a) and TO-Zr (b) specimens, in Ringer's solution at $37^{\circ} \mathrm{C}$. 



Fig. 15: Typical cross-sectional profiles of the wear tracks produced on the TO-Ti (a) and TO-Zr (b) specimens during tribocorrosion under various contact loads. 


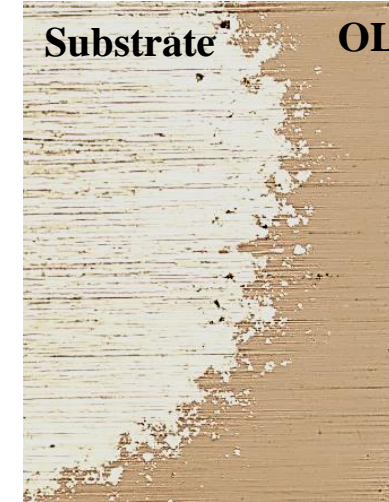

(a) $10 \mathrm{~N}$





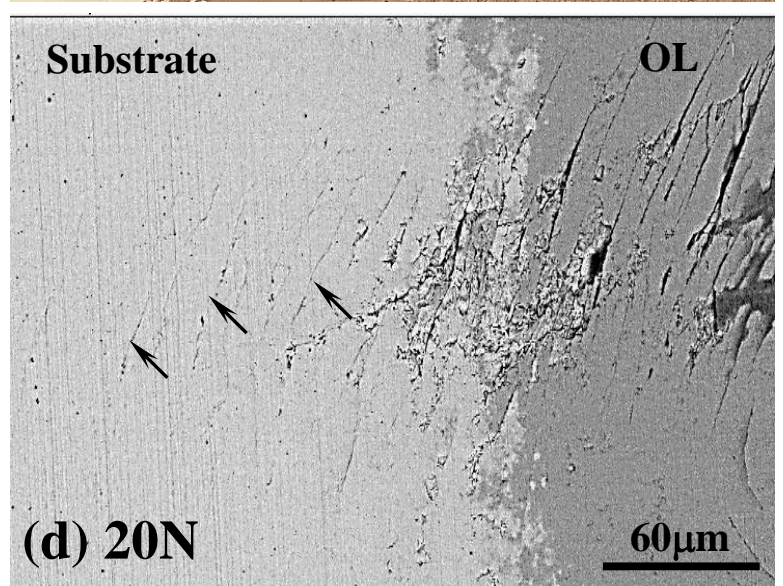

Fig. 16: Microscopic images of the zoom-in view of ball craters made on the wear tracks produced on the TO-Zr specimen during tribocorrosion in Ringer's solution at $37^{\circ} \mathrm{C}$ under (a) $10 \mathrm{~N}$, (b) $15 \mathrm{~N}$, (c) and (d) $20 \mathrm{~N}$ contact loads, showing the wear tracks, the OL and substrate beneath each wear track. Arrows show the penetration of cracks in the substrate. 


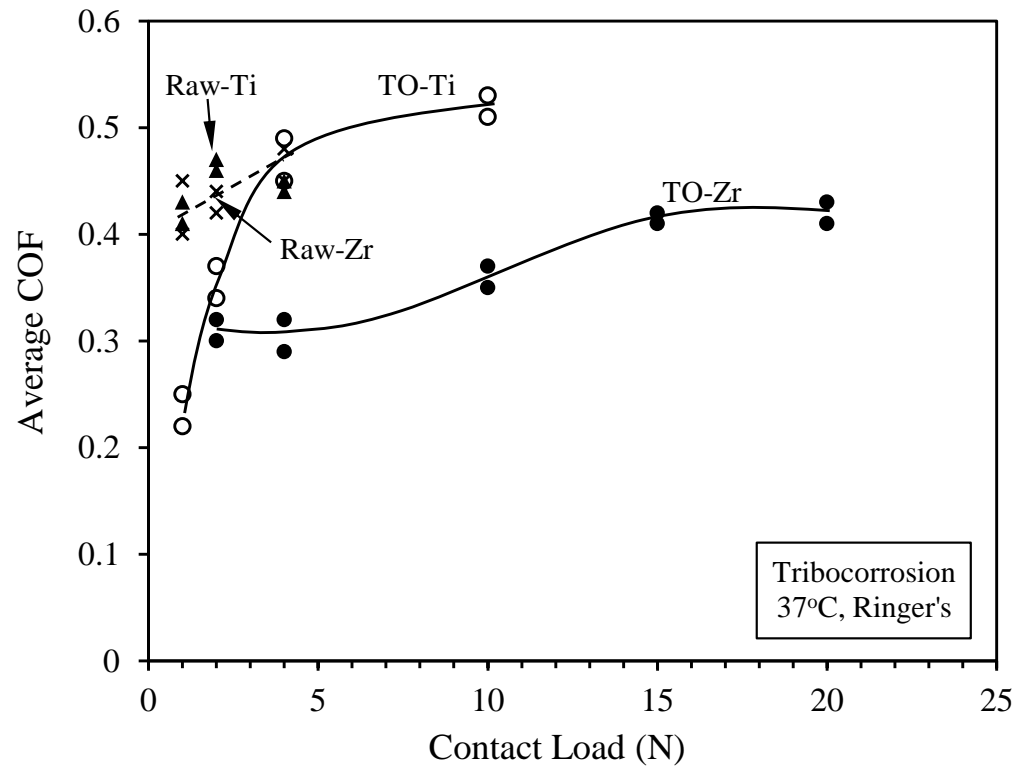

Fig. 17: Measured average coefficient of friction for the test specimens under tribocorrosion conditions. 

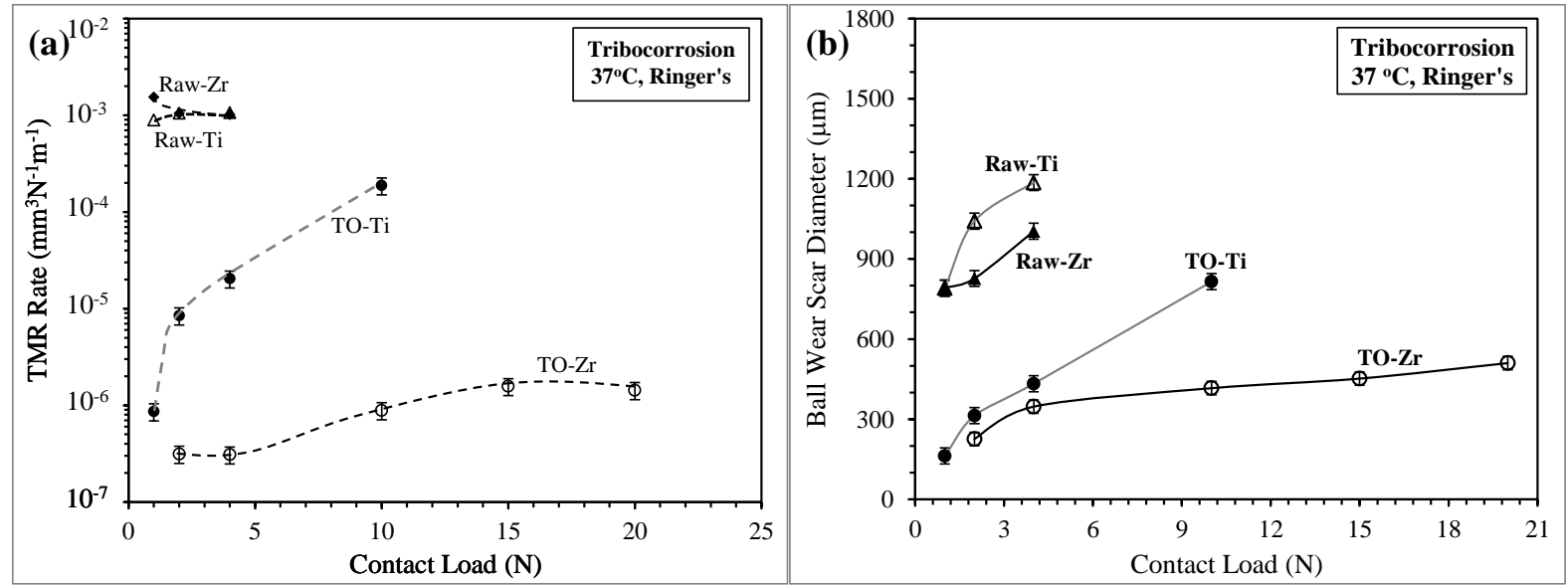

Fig. 18: Measured total material removal (TMR) rate from the corrosion wear track (a) and ball wear scar diameter (b) for the TO-Ti and TO-Zr specimens under tribocorrosion conditions. 